\title{
EXPERIMENTAL STUDIES OF BEHAVIORAL EFFECTS OF MEPROBAMATE ON NORMAL SUBJECTS
}

\author{
By Donald G. Marquis, E. Lowell Kelly, James G. Miller, \\ Ralph W. Gerard, and Anatol Rapoport \\ University of Michigan, Ann Arbor, Mich.
}

With the increasing use of meprobamate, it is important to know its effects on the behavior of relatively normal subjects, on persons who take the drug without discontinuing their usual activities. We need detailed information about the effects of the drug on those common but complex acts in which most people engage as part of their daily lives. One of these activities-potentially dangerous if not properly carried out-is driving an automobile. How does meprobamate affect the motor skills, the sensory processes, and the judgment necessary for safe driving? Does meprobamate in usual doses, alone or in combination with a martini or a drink of whiskey, make it likely that a driver will endanger his own life or the lives of others? The answers to these and related questions have become increasingly important in view of the rapid changes occurring in our modern world.

Although some information on these issues can be obtained from general observation and from subjective reports, our knowledge about the drug's effects will be much sounder if the data are obtained under standardized and controlled conditions. Our research, including studies of reaction time, driving skills, steadiness, and visual performance, was designed to accomplish this.

\section{Drug Administration}

Fifty adult subjects were tested on 5 successive days, on each of which they received one of the following doses: (1) a placebo (lactose, $1400 \mathrm{mg}$.); (2) meprobamate $(800 \mathrm{mg}$ ) ; (3) dextroamphetamine sulfate (15 mg.); (4) meprobamate $(800 \mathrm{mg}$.) plus alcohol ( $2 \mathrm{oz}$. of 86-proof whiskey); and (5) a placebo (lactose, $1400 \mathrm{mg}$.) plus alcohol (2 oz. of 86-proof whiskey). The placebo, meprobamate, and dextroamphetamine sulfate were in capsules and were not identified to the subjects. There were 2 capsules of meprobamate in each treatment, 2 capsules for the placebo, and 1 for the dextroamphetamine sulfate. The whiskey was administered undiluted in a pony glass. Since the experimenters were, therefore, necessarily a ware of some of the treatments given, the research design was not a "double blind," the procedure at present so highly regarded for evaluating drugs. Because we were using objective behavioral measures, however, the blind method did not seem so essential as when effects of drugs on patients are to be rated or evaluated clinically. It seems unlikely that the information unavoidably revealed to the experimenters could have affected the scores on any of our procedures. Perhaps an ultimate objective quantification of such measures of change may eliminate the need for elaborate double-blind controls. 


\section{Testing Procedures}

All the subjects were tested in small rooms in the Ann Arbor Veterans Administration Hospital. Testing was done on consecutive working days, omitting week ends, and each subject was tested at approximately the same hour each day. On the first day of testing the experimenter explained to the subject that the purpose of the experiment was to learn the effects of certain drugs on driving, and that the drugs administered would have no serious effects. It is likely that most of the paid subjects knew through "the grapevine" that meprobamate and alcohol were two of the drugs to be used, but they were not so informed by the experimenters. In order to permit the most efficient use of time, subjects were seen in pairs. While one was operating the auto trainer in one room with one experimenter, the other was being given the remaining tests in another room by a second experimenter. The tasks were then switched.

Upon entering the waiting room the subjects were given one of the drugs or placebos; a 30-minute waiting period was allowed for it to take effect. The order of presentation of the drugs over the 5-day period varied from subject to subject in such a way that each treatment occurred equally often at each stage of practice, and each treatment followed every other treatment with equal frequency. Each day the subject received a different treatment, so that at the end of the 5-day testing period he had received them all. During the waiting period on the first day the subjects were interviewed for background and personal information and were given a 15-minute practice session on the driving task. Half received the interview first, and half received the driving practice first.

\section{Subjects}

Of the 50 subjects, 36 were men and 14 were women. The range in age was from 21 to 50,30 of the subjects being between 21 and 29 . Twenty-nine were college students, 9 were patients with medical (not neuropsychiatric) illnesses in a Veterans Administration hospital, 5 were patients in a neurosis center, and 7 were Veterans Administration employees. Most of these persons were normal, in the sense that they did not suffer from obvious personality difficulties or mental illnesses, and none was psychotic. Thirty-seven replied "no" to the question, "Have you or has any nember of your family been bothered by fits, faints, or nervousness?" Of the remainder, 8 gave a personal history, 3 a family history, and 2 both a personal and a family history of such symptoms. It appeared to us that this probably was a reasonably representative sample in terms of the mental status of the types of persons at present receiving meprobamate.

Of those subjects who were hospital patients, 9 had been hospitalized less than 1 month, 1 for 1 month, 1 for 2 months, 2 for from 3 to 5 months, and 1 for between 6 months and a year.

All subjects were volunteers. The student subjects were paid, while the others were not.

Because of the relationships of body weight to drug effects, the subjects' weights were taken. Eleven weighed between 90 and $124 \mathrm{lb}$., 11 between 125 
and 139, 4 between 140 and 154, 9 between 155 and 169 , and 9 between 170 and 184. The remaining 6 weighed more than $185 \mathrm{lb}$.

Thirty-four of the subjects were accustomed to driving daily, 7 drove at least weekly, and only 9 drove seldom or not at all.

Forty of the subjects reported that they had never taken tranquilizing drugs; the other 10 had taken them only infrequently. Thirteen said they were moderate drinkers, 31 reported they were light drinkers, and 6 said they did not drink alcohol at all. None admitted being a heavy drinker or having a history of alcoholism.

\section{Apparatus and Results}

For the driving tests, the American Automobile Association's "Auto Trainer" was used (FIGURE 1). This apparatus consists of 2 parts: the first includes all the controls of a conventional-shift automobile-starter button, speedometer, steering wheel, gear-shift lever, ignition key, and accelerator, brake, and clutch pedals; the second part is a treadmill-like belt about 10 feet long, which extends from the front of the control unit. The belt, painted to resemble a tortuous roadway, revolves when the controls are in gear, the speed being controlled by the accelerator. In our experiment, however, the apparatus was modified so that the speed could be set by the experimenter's controls at a constant fast

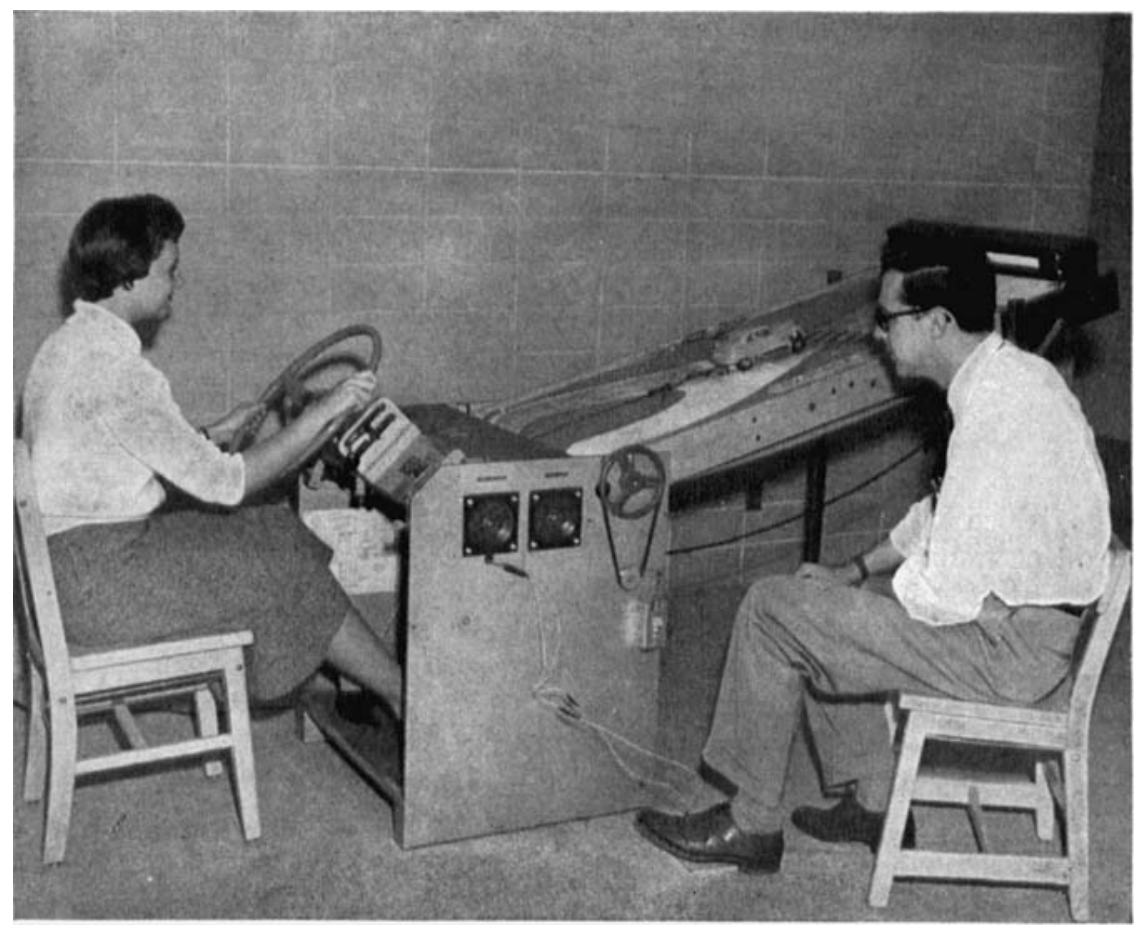

Figure 1. American Automobile Association's Auto Trainer, used for the driving test. 
rate (equivalent to approximately $20 \mathrm{mph}$ ) or a slow rate (approximately 10 $\mathrm{mph}$ ).

A small model car, the steering mechanism of which is controlled by the steering wheel of the control unit, rests on the belt, its wheels turning as the belt revolves, and the speed of the belt determines its apparent speed. The task of the subject is to steer the car so that it remains in the center of the roadway painted on the belt. A red and a green light are situated at the far end of the belt unit. When the green light is on, the driver is to proceed; when the red light appears, he is to stop the car as rapidly as possible by depressing the brake.

An accuracy counter, a reaction timer, a trial timer, and speed controls face the experimenter at the side of the control unit, out of sight of the subject. A foot switch with which the experimenter can turn on the red light is also connected to the side of the unit. Large staples are embedded in the "roadway" every 3 inches. If the car is kept in the center of the roadway, it makes contact with the staples, completing an electrical circuit and advancing the accuracy counter 1 unit. The reaction timer measures in hundredths of a second the time elapsed between the appearance of the red light and the brake-pressing response.

The subjects were given trials as follows: 20 revolutions of the belt at a fixed slow speed; 20 at a fixed fast speed; and 20 at a speed controlled by the subject. Six reaction-time determinations were interspersed irregularly through each of the 3 trials.

On the driving test, scores were obtained for accuracy at the fixed low speed, at the fixed high speed, and at the variable speed controlled by the subject. The unit of measurement was the number of staples over which the car passed. It will be remembered that the staples were embedded in the center of the roadway so that the subject had to keep the car in the middle of the road to activate the accuracy counter. In addition, a time score was obtained, indicating the time required for each trial when the subject was controlling his own speed. During this phase of the test the subject was asked to drive as rapidly and accurately as he could. A derived score was also figured-the ratio of the difference between the accuracy score at low fixed speed and the accuracy score at subject-controlled speed, divided by the time score. This speed-accuracy ratio, which indicated the degree to which speed was sacrificed for accuracy, or vice versa, may be interpreted as a measure of judgment. Scores on the driving-test measures and on all other tests under the various drug conditions, as compared with the placebo condition, are presented in TABLE 1 .

Reaction times for the brake-pressing response were taken while the car was being driven at low fixed speed, at fast fixed speed, and at variable speed. As can be seen in TARLE 1, none of the drug treatments produced a significant change on the speed of reaction, nor on any of the other driving-test scores*.

\footnotetext{
* The lack of significant difference in braking time under meprobamate and under placebo is consistent with our earlier study of visual reaction time in 20 subjects under laboratory conditions. The reaction times of each subject were measured in a session twice daily for 3 successive days. Each session consisted of 10 separate reaction-time measurements after 3 practices. No drug was given the first and third days, but the trials on the second day were conducted 6 and 12 hours after the subjects had taken $800 \mathrm{mg}$. of meprobamate. The findings indicated that meprobamate does not lengthen visual reaction time so measured.
} 
TABLE 1

Mean Differences Between Scores Under Each of Four Drug Conditions and Under Placebo

\begin{tabular}{|c|c|c|c|c|}
\hline \multirow{2}{*}{ Tests } & \multicolumn{4}{|c|}{$\begin{array}{c}\text { Differences between scores in standard deviation } \\
\text { of placebo action }\end{array}$} \\
\hline & Meprobamate & $\begin{array}{c}\text { Meprobamate } \\
\text { and alcohol }\end{array}$ & $\begin{array}{l}\text { Placebo and } \\
\text { alcohol }\end{array}$ & $\begin{array}{l}\text { Dextro- } \\
\text { amphetamine } \\
\text { sulfate }\end{array}$ \\
\hline \multicolumn{5}{|l|}{ Driving tests } \\
\hline Fixed low speed. & +0.16 & +0.04 & -0.05 & -0.07 \\
\hline Fixed high speed. & +0.06 & +0.04 & +0.06 & +0.01 \\
\hline Variable speed. & +0.04 & -0.08 & +0.07 & +0.02 \\
\hline Time & & & & \\
\hline Variable speed. & -0.16 & -0.08 & -0.10 & -0.08 \\
\hline $\begin{array}{l}\text { Judgment....... } \\
\text { Reaction time }\end{array}$ & +0.05 & +0.07 & -0.05 & -0.06 \\
\hline Fixed low speed. & -0.15 & -0.19 & -0.21 & +0.17 \\
\hline Fixed high speed. & -0.04 & -0.12 & +0.04 & $\begin{array}{l}10.20 \\
+0.20\end{array}$ \\
\hline Variable speed. & -0.10 & -0.27 & -0.14 & +0.06 \\
\hline $\begin{array}{l}\text { Palmar perspiration test } \\
\text { Steadiness'test }\end{array}$ & $-0.35^{*}$ & +0.05 & -0.08 & -0.22 \\
\hline $\begin{array}{l}\text { Steadiness'test } \\
\text { Largest hole. . }\end{array}$ & +0.06 & -0.09 & -0.26 & \\
\hline $\begin{array}{l}\text { Largest hole........ } \\
\text { Next to largest hole. }\end{array}$ & $\begin{array}{l}10.00 \\
+0.03\end{array}$ & $\begin{array}{l}-0.09 \\
-0.09\end{array}$ & $\begin{array}{l}-0.20 \\
-0.20\end{array}$ & $\begin{array}{l}-0.19 \\
-0.09\end{array}$ \\
\hline Medium hole....... & +0.04 & -0.14 & $-0.30^{*}$ & -0.01 \\
\hline Next to smallest hole. & -0.16 & -0.13 & -0.16 & -0.07 \\
\hline Smallest hole.... & +0.04 & +0.03 & -0.01 & +0.17 \\
\hline \multicolumn{5}{|l|}{$\begin{array}{l}\text { Visual tests } \\
\text { Depth perception }\end{array}$} \\
\hline $\begin{array}{c}\text { Depth perception } \\
\text { Distant....... }\end{array}$ & +0.07 & +003 & +007 & +003 \\
\hline Acuity & +0.08 & & & +0.05 \\
\hline $\begin{array}{l}\text { Distant. . } \\
\text { Near }\end{array}$ & -0.05 & -0.09 & 0.0 & -0.05 \\
\hline Near ..... & -0.09 & -0.09 & -0.09 & +0.05 \\
\hline $\begin{array}{l}\text { Vertical phoria } \\
\text { Distant...... }\end{array}$ & & & & \\
\hline $\begin{array}{l}\text { Distant...... } \\
\text { Near. . . . . }\end{array}$ & $\begin{array}{l}+0.08 \\
+0.15\end{array}$ & 0.0 & $\begin{array}{l}-0.08 \\
-0.08\end{array}$ & $\begin{array}{c}0.0 \\
+0.08\end{array}$ \\
\hline Lateral phoria & T. & & & \\
\hline Distant.... & 0.0 & -0.06 & -0.06 & -0.06 \\
\hline Near & -0.07 & 0.0 & +0.04 & -0.07 \\
\hline
\end{tabular}

Symbols: + indicates that the drug effect was more favorable than the placebo effect; - indicates that the placebo effect was more favorable than the drug effect. chance.

* The probability is less than one in a hundred that this result could have occurred by

In order to secure a measure of autonomic response, as an index of anxiety, the perspiration during the driving test was recorded.

The technique used is an adaptation of the one used by $\mathrm{O}$. H. Mowrer. The subject's thumb is swabbed with a solution of ferric chloride $(13 \mathrm{gm}$. of anhydrous ferric chloride in $400 \mathrm{cu}$. $\mathrm{cm}$. of chemically pure acetone, with 3 drops of hydrochloric acid added to stabilize the solution). A small square of paper, soaked in a 5 per cent aqueous solution of tannic acid and allowed to dry, is placed on the thumb and held firmly by a small foam-rubber pad taped to the subject's thumb. The pressure with which the pad is taped to the thumb is roughly controlled by attempting to equalize the amount of compression of the pad for every administration. The pad is worn throughout the driving test. 
As the subject perspires, the ferric chloride dissolves and makes a stain on the paper. The darkness of the stain is proportional to the amount of sweating.

A score is obtained by placing the ferric chloride paper over the half-inch aperture in a transmission-type photometer and reading the percentage of light transmission of the darkest area. One hundred per cent transmission is set at the amount of light transmitted by the nonstained part of the paper, and the score is expressed in percentage of this value.

The temperature and relative humidity of the testing room were also recorded during all the testing sessions, so that these variables could be controlled statistically in evaluating the measure of perspiration.

The results of the perspiration measure were clear-cut. Perspiration was significantly greater under meprobamate, as compared with the placebo. Dextroamphetamine sulfate and alcohol did not produce any definite effect. The results with meprobamate were exactly contrary to expectation, so we double checked to determine that there had been no error in recording or computing the scores.

Intercorrelations between palmar sweating and room humidity and temperature were so low under meprobamate and under placebo that correlated changes in these variables could not explain the difference. Moreover, our data analysis showed a similar effect in males and females, so the over-all results cannot be explained by any differential; such as degree of vasomotor stability, between the sexes. Males sweated more than females under all conditions. It is unclear in the literature and to us whether the perspiration test is, as usually sug-

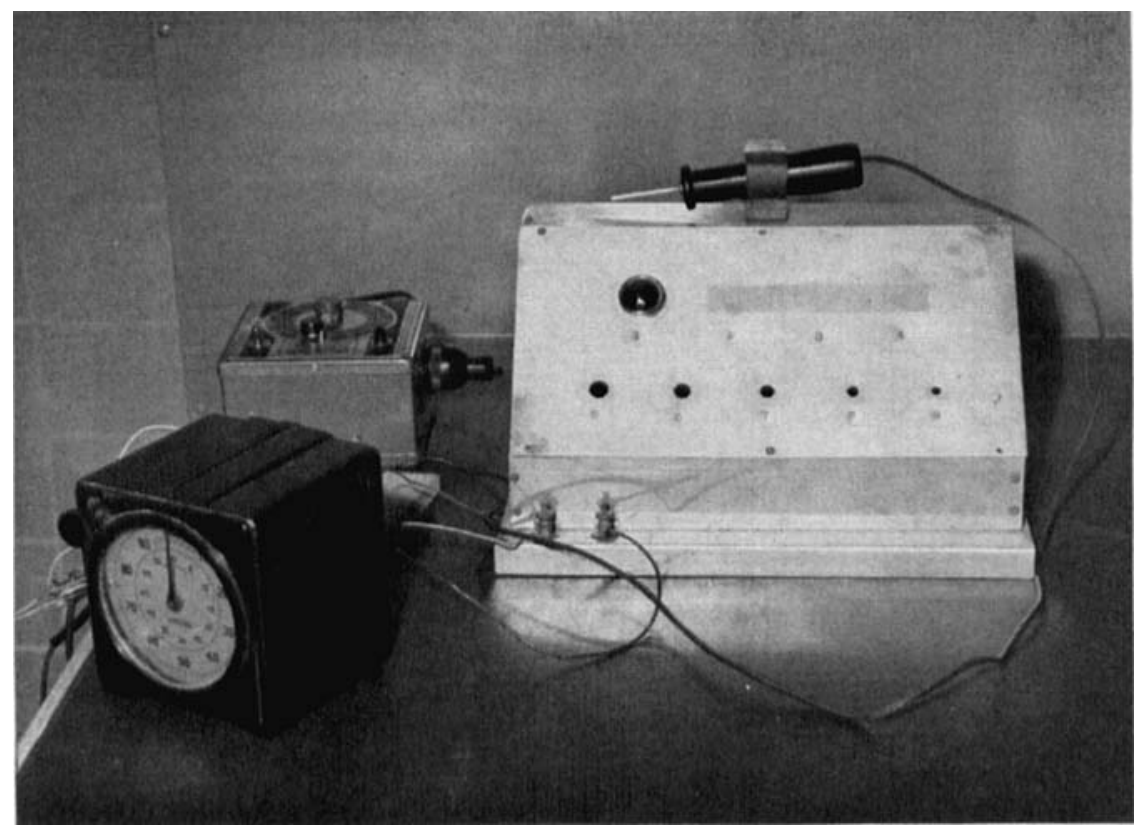

Frgure 2. Apparatus for the Whipple Steadiness 'Test. 
gested, a measure of anxiety, or whether it may be related more to muscular exertion or some other function.

The steadiness test used is an adaptation of the Whipple Steadiness Test (FIGURE 2). The test panel contains a series of holes decreasing in size from $7 / 16$ in. to $3 / 16$ in. The subject is asked to insert a round metal stylus $1 / 8$ in. in diameter into each of the holes and to hold it there for $15 \mathrm{sec}$. without letting it touch the sides of the hole. The apparatus is wired so that a timer is activated whenever the stylus touches the sides of the hole during the 15-sec. test period.

Scores were obtained for 3 trials on each of the 5 holes, representing the total amount of time that the stylus touched the rim of the hole. The scores were weighted to compensate for the varying difficulties of task for each hole, in making direct comparisons and to facilitate combination of the scores from the different-sized holes. For weighting, the scores for the $7 / 16$-in. hole were multiplied by 10 ; the $6 / 16^{-i n}$. hole, by 4 ; the $5 / 16$-in. hole, by 1 ; the $4 / 16^{-i n}$. hole, by $1 / 4$; and the $3 / 16$-in. hole, by $1 / 10$.

With placebo and alcohol there was a significant impairment of steadiness for the medium-size hole, but not with meprobamate or dextroamphetamine sulfate. There was a similar impairment (nearly to the level of significance) for the other 3 of the 4 largest holes. There was a suggestion that meprobamate tends to counteract alcohol.

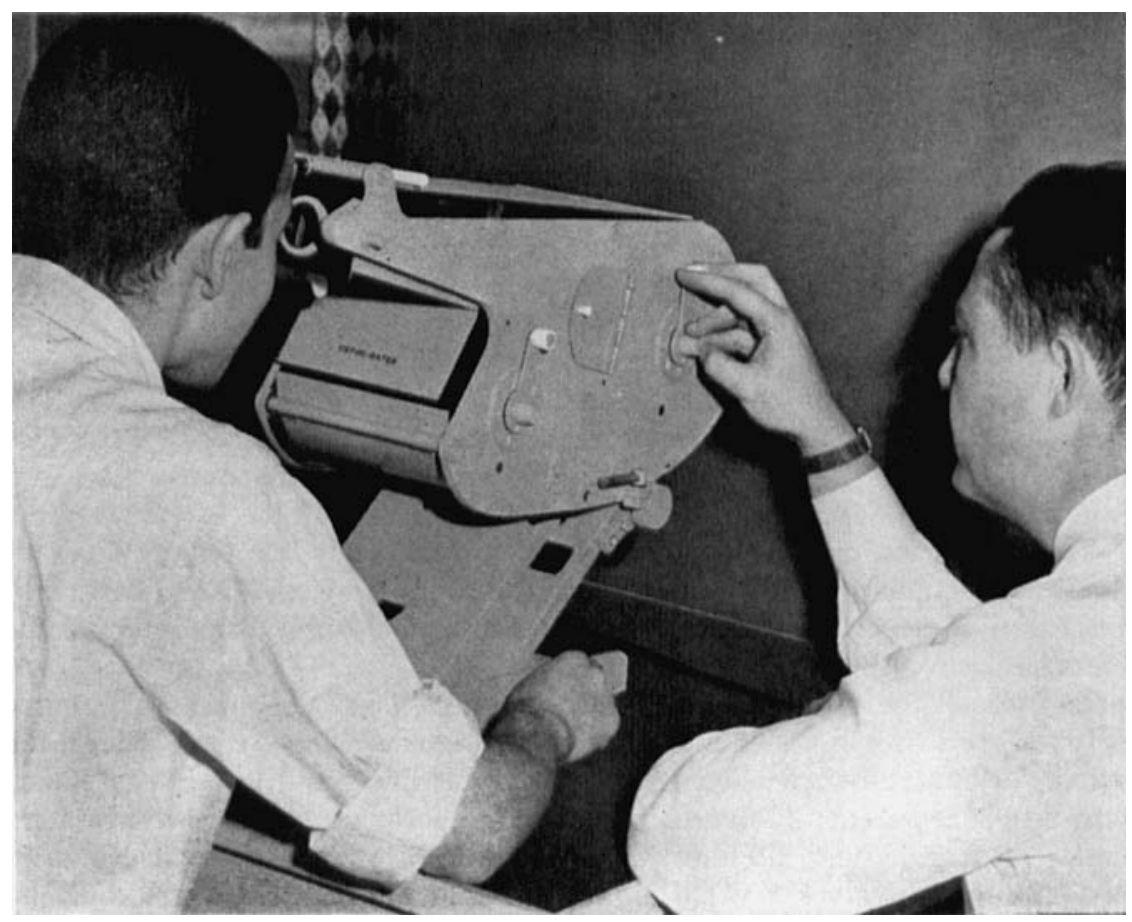

Figure 3. Bausch and Lomb master-model Ortho-rater. 
For the visual tests we employed the master-model Ortho-rater (FIGURE 3) constructed by the Bausch and Lomb Optical Company, Rochester, N. Y. This device is designed to present slides for testing various visual functions, with distance and illumination controlled. It consists of 2 octagonal slideholding drums set inside a boxlike apparatus. A binocular eyepiece is located at one end of the box. One of the drums is much closer to the eyepiece than the other and is used for testing near vision; the farther drum is used for testing distant vision. The test slides are fastened to the drum and are easily changed by rotating the drum with an external handle. Standard Ortho-rater testing procedures were used for 7 visual tests.

Acuity was determined for both far and near vision; depth perception scores were determined for distant vision only. Vertical and lateral phorias for both near and far vision were also measured. Phoria scores indicate the relative posture or muscular balance of the eyes in relation to each other under conditions of controlled accommodation. A perfect vertical phoria score indicates that the horizontal midline in both the right and left visual fields is in the same axis. A perfect lateral phoria score indicates the same for the vertical midline. In TABIE 1 the plus scores would indicate exophoria; minus scores would indicate esophoria.

The results of the visual tests yielded no significant differences between the drugs and the placebo.

\section{Summary of Meprobamate Effects}

In the analysis of results, using the critical ratio of correlated measures, we compared all possible pairs of treatments on all test scores, as well as temperature and humidity readings during the perspiration test - a total of 230 critical ratios and correlation coefficients. The same statistical analyses were also done separately for the males alone and for the females alone. No clear sex differences in the effects of meprobamate were demonstrated; the results, therefore, are reported for the total group of subjects.

The intercorrelations between scores on all 23 test variables were also obtained for the placebo condition and for the meprobamate condition. The several measures of accuracy, of reaction time, and of steadiness were highly intercorrelated, suggesting that each set of these alternate measures validly samples a single domain.

The correlation coefficients between the scores on any one test on different days, that is, under different drug treatments, ran between 0.45 and 0.90 , with a median of 0.68 . This indicates a satisfactory reliability for the different measures.

In TABLE 1 the column headed "Meprobamate" shows the mean differences between the scores obtained under meprobamate and placebo conditions on the driving tests, the perspiration test, and the steadiness and visual tests. The plus scores represent differences in which the performance is more favorable under meprobamate. Deciding what direction of effect is favorable on any test naturally involves a value judgment but, in most cases, there could be 
TABLE 2

Mean Differences Between Scores Under Meprobamate and Alcuhol, and Under Placebo and Alcohol.

Differences Between Scores in Standard Deviation of Placebo and Alcohol Action

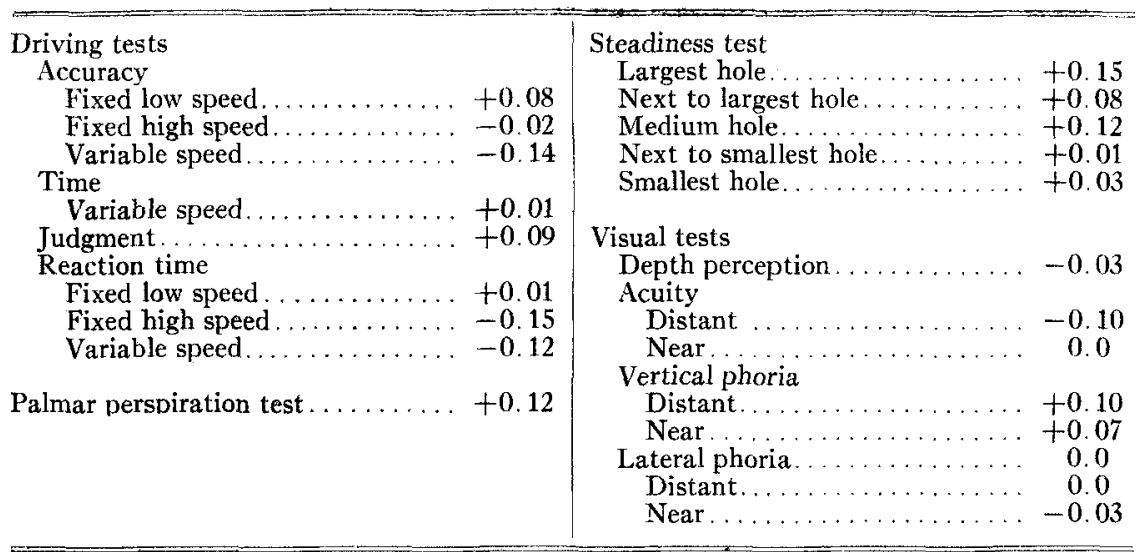

Symbols: + indicates that the meprobamate and alcohol effect was more favorable than the placebo and alcohol effect; - indicates that the placebo and alcohol effect was more favorable than the meprobamate and alcohol effect.

little argument. The only significant difference here is the greater amount of perspiration with meprobamate. As we have noted, this result is unexpected, and its interpretation is not clear.

What are the effects of alcohol as contrasted with those of meprobamate and alcohol together? In TABLE 1 the columns headed "Meprobamate and alcohol" and "Placebo and alcohol" show the effects of these drugs as compared with the placebo on all of the tests. The only statistical significance revealed is the effect of alcohol on the measure of steadiness. Perhaps the absence of other clear-cut effects of alcohol on driving and vision can be attributed to the relatively small dosage of less than $1 \mathrm{oz}$. of alcohol. Comparing the results for the combined meprobamate and alcohol offers no evidence that the combination has any more unfavorable effects than alcohol alone.

A direct comparison of the performances on the same tests under alcohol and under alcohol plus meprobamate yields the findings shown in TABLE 2. The plus scores indicate more favorable performance under combined alcohol and meprobamate as compared with alcohol alone. None of the differences is statistically significant.

\section{Examination Performance and Anxiety}

Another research study provides more general evidence for the absence of deleterious effects of meprobamate on normal functioning. This experiment was carried out in collaboration with Wilbert McKeachie of the Department of Psychology at the University of Michigan. In connection with a regular mid-term examination in a college psychology course, a class of 276 students, 
after being assured it would have no serious effects, agreed to take a pill of unstated composition 1 hour before the examination*. Selected at random, 138 of the students received $400 \mathrm{mg}$. of meprobamate, and 138 received a placebo (5 gm. of acetyl salicylic acid). Performance on the examination was not impaired for those who received meprobamate; indeed, it was slightly better, as might be expected, since it is obvious that anxiety and apprehension interfere with efficiency on examinations. Support for this interpretation comes also from the answers to 5 questions at the end of the examination, asking about worry and stress during the period. The students who received meprobamate reported somewhat less anxiety than the others, but the difference was not clearly significant.

An unexpected finding in these results was that meprobamate had a greater effect on females than on males, both in improving examination scores and in reducing anxiety. In the research on driving, we also found that dextroamphetamine sulfate, and perhaps other drugs, produced greater performance effects on females than on males. Since body weight was not taken into account in the dosage, the interpretation of these findings is not clear. However, sex differences in drug action are well known, as, for example, in the hypnotic effects of barbiturates.

\section{Summary}

The primary finding of these studies is that meprobamate alone, even in double the usual dosage, produces no behavioral toxicity in our subjects as measured by our tests of driving, steadiness, and vision. Meprobamate significantly increases sweating, an unexpected and unexplained finding.

Our study also indicates that, while alcohol definitely impairs performance on some tests, combining meprobamate with the alcohol does not significantly add to this unfavorable effect on any test. Our data give no grounds for preventing persons under the usual dosages of meprobamate from driving automobiles, or even from driving under meprobamate after drinking alcohol in amounts that would not ordinarily affect driving ability.

\section{Acknowledgments}

The authors thank Sidney Perloe and Richard Metz, who administered the tests and assisted throughout the research, and Lillian Kelly, who did much of the data analysis. We also express our gratitude to the United States Veterans Administration Hospital in Ann Arbor for providing space and many of the subjects for this study, and to the Veterans Readjustment Center for providing subjects.

\section{Discussion of the Paper}

Question: I should like to put a faint note of caution on the all-sweeping summary that the doses of meprobamate do not interfere with judgment or mechanical skill, or that doses of meprobamate plus alcohol are not in any

\footnotetext{
* We recognize, of course, that such assurances could have a suggestion effect on the outcome. but they were obviously necessary in order to obtain co-operation of the subjects.
} 
way synergistic. I feel that the enthusiasm for the experiment, while it is excellent for the first series of tests, certainly does not take into consideration what Berger has already emphasized, namely, that with meprobamate there is a considerable latent period before action takes place. Many people who take meprobamate do so, not once a day, but three, four, or more times a day for several days. At the end of such a period of dosage the residual effects from many partially destroyed doses of meprobamate could be considerably greater than even the one double dose. I cannot question the results as presented, but $I$ do advise caution in their application.

D. G. MARQUIS: Certainly we have no desire to generalize beyond the reasonable limits represented by the particular test data. The latent period of meprobamate is no more than $30 \mathrm{~min}$., and we used a 30 -min. waiting period. The tests extended over an hour following this waiting period. Since the usual dosage is 1 pill every 4 hours, we were given no reason to believe that there would be a cumulative effect any greater than the effect of 2 pills taken simultaneously.

Question: I wonder if Marquis has any comments to make regarding the distribution within the group that averaged out as nonspecific. Were there any patterns that suggested that some people behaved differently than others under these conditions?

D. G. MARquis: Certainly there were individual differences, but there is no way to evaluate their significance except by a system of subgrouping of the individuals. While we did find differences in magnitudes, such as the fact that women do not sweat as much as men, the drug effects were always in the same direction. 